\title{
Var transcription profiling of Plasmodium falciparum 3D7: assignment of cytoadherent phenotypes to dominant transcripts Uta Gölnitz ${ }^{\dagger}$, Letusa Albrecht ${ }^{\dagger}$ and Gerhard Wunderlich*
}

\author{
Address: Department of Parasitology, Institute of Biomedical Sciences, University of São Paulo, Avenida Prof. Lineu Prestes 1374, São Paulo - SP, \\ Brazil \\ Email: Uta Gölnitz - uta.goelnitz@gmx.de; Letusa Albrecht - letusa@usp.br; Gerhard Wunderlich* - gwunder@usp.br \\ * Corresponding author †Equal contributors
}

Published: 14 January 2008

Malaria Journal 2008, 7:14 doi:10.1186/1475-2875-7-14

This article is available from: http://www.malariajournal.com/content/7///14

(C) 2008 Gölnitz et al; licensee BioMed Central Ltd.

This is an Open Access article distributed under the terms of the Creative Commons Attribution License (http://creativecommons.org/licenses/by/2.0), which permits unrestricted use, distribution, and reproduction in any medium, provided the original work is properly cited.
Received: 27 September 2007

Accepted: 14 January 2008

\begin{abstract}
Background: Cytoadherence of Plasmodium falciparum-infected red blood cells is mediated by var gene-encoded $P$. falciparum erythrocyte membrane protein-I and host receptor preference depends in most cases on which of the 50-60 var genes per genome is expressed. Enrichment of phenotypically homogenous parasites by panning on receptor expressing cells is fundamental for the identification of the corresponding var transcript.

Methods: $P$. falciparum 3D7 parasites were panned on several transfected $\mathrm{CHO}$-cell lines and their var transcripts analysed by i) reverse transcription/PCR/cloning/sequencing using a universal DBL $\alpha$ specific oligonucleotide pair and ii) by reverse transcription followed by quantitative PCR using 57 different oligonucleotide pairs.

Results: Each cytoadherence selected parasite line also adhered to untransfected $\mathrm{CHO}-745$ cells and upregulation of the var gene PFD995/PFDI000c was consistently associated with cytoadherence to all but one $\mathrm{CHO}$ cell line. In addition, parasites panned on different $\mathrm{CHO}$ cell lines revealed candidate var genes which reproducibly associated to the respective cytoadherent phenotype. The transcription profile obtained by RT-PCR/cloning/sequencing differed significantly from that of RT-quantitative PCR.

Conclusion: Transfected $\mathrm{CHO}$ cell lines are of limited use for the creation of monophenotypic cytoadherent parasite lines. Nevertheless, 3D7 parasites can be reproducibly selected for the transcription of different determined var genes without genetic manipulation. Most importantly, var transcription analysis by RT-PCR/cloning/sequencing may lead to erroneous interpretation of var transcription profiles.
\end{abstract}

\section{Background}

Plasmodium falciparum the causative agent of tropical malaria still kills over one million people per year, mostly children under five years in sub-Saharan Africa [1]. One major virulence factor of this parasite is the highly variant Plasmodium falciparum erythrocyte membrane protein-1
(PfEMP-1) family [2]. Members of this family appear at the surface infected red blood cell, during the trophozoite stage. Their large, highly variable ectodomains, consist of several subdomains (termed Duffy binding-like, DBL, and cystein rich interdomain regions, CIDR), which interact with a number of cellular host receptors such as CD36, 
ICAM-1, CSA, PECAM, E-Selectin, VCAM and others (reviewed by [3]). This interaction causes the retention of mature blood stage forms in the tissue which express the cited receptors and is believed to result in pathogenic processes associated with malaria [4]. Each infected red blood cell (IRBC) displays only one PfEMP-1 allele at its surface and this selective expression is controlled at the transcriptional level [5] by allelic exclusion [6,7]. It is believed that only one of the approximately fifty var promoters is active and concomitantly localized to a specific compartment at the nuclear periphery [8-10]. The transcriptional activity of var promoters is apparently determined by histone modifications [11-14], which may then permit or inhibit the recruitment of yet largely unknown transcription factors. The pattern of var transcription is inherited through several generations $[15,16]$ despite the absence of DNA methylation [17] and switches in the transcription result in altered antigenic phenotypes.

Several groups tried to correlate disease outcomes with adhesive IRBC phenotypes, with sometimes contradicting outcomes for ICAM-1 and/or CD36-mediated adhesion $[18,19]$. The excessive CSA-mediated adhesion of IRBC was clearly correlated to severe malaria outcomes in primigravids [20] and the PfEMP1 $1_{\mathrm{csa}}$-encoding var2csa gene, upregulated in CSA-adhesive parasites, was analysed in detail [21] and the structure of its crucial DBL $\gamma$ domain mapped [22].

So far, few studies associated the var genes to adhesive phenotypes in cultivated field isolates. One Indian isolate was obtained after enrichment of an ICAM-1-adhesive phenotype [23]. Parasites obtained from the placenta of primigravid women frequently transcribe var2csa and adhere to CSA found in abundance on syncithiotrophoblasts [24]. The primary var transcript sequence can be of importance for the design of specific PfEMP-1 domains that may be used as a vaccine inducing antibodies, which then inhibit or decrease cytoadherence of IRBCs, as shown for CD36-binding CIDR [25] and CSA-binding DBL $\gamma$ domains [26]. Also, for the elucidation of the epigenetic control mechanisms that orchestrate var gene transcription it may be of interest to reproducibly obtain parasites with a defined var locus switched on or off in its native, unmodified genomic context. The enrichment of adhesive phenotypes is achieved by the panning procedure, where cytoadherent IRBCs are incubated either on isolated receptor molecules [15] or on receptor-expressing cells, such as amelanotic melanoma cells expressing CD36 [27], Saimiri brain endothelial cells (SBEC) expressing CSA and/or CD36 and ICAM-1 [28], human lung endothelial cells (HLEC) expressing CD36 and ICAM-1 [29], human choriocarcinoma cells expressing CSA and CD36 [30] or Chinese hamster ovary cells $(\mathrm{CHO})$ transfected with the respective receptors [31]. After several rounds of panning and amplification of the parasites a sufficiently high homogeneity of the cytoadherent phenotype is obtained which then permits functional or transcript analysis. The $\mathrm{CHO}$ cell lineages are especially convenient since they express the receptors in a constitutive fashion without the need of external stimulation as it is the case for SBEC or HLEC. However, the CHO cell lineage has the disadvantage that there is a - to date unknown - receptor which is recognized by equally unknown parasite encoded PfEMP1 or other molecules which may mask the desired receptorligand interaction [32]. In order to estimate the viability of the transfected CHO cell lines in the enrichment of relevant adhesive phenotypes and later transcript analysis, var gene transcription was monitored of different $P$. falciparum 3D7 parasite lines panned on receptors expressed on stably transfected CHO-cell lines [31,33]. Var transcripts were then analysed by reverse transcription followed by quantitative real time PCR (RT-qPCR). In addition, we also evaluated if the frequently used approach of reverse transcription followed by PCR, fragment cloning and sequence read counting (RT-PCRcsc), is reliable to estimate dominant var transcripts in $P$. falciparum. This issue is of major importance since field isolates can currently be tested for their var transcripts only by this approach.

\section{Methods \\ Parasites and cell lines}

Plasmodium falciparum 3D7 parasites [34], a cloned line derived from isolate NF54, were cultured and sorbitolsynchronized according to previously published methods [35,36]. Stable transfectants of CHO expressing CSA (CHO-K1), CD36, E-Selectin, ICAM-1, VCAM [31,33] and the CSA negative CHO variant pgsA (CHO-745, [37,38], a gift from Artur Scherf, Institut Pasteur, Paris) were cultured in RPMI 1640 containing 10\% FCS, $40 \mathrm{mg} / \mathrm{L}$ gentamycin in a $5 \% \mathrm{CO}_{2}$ atmosphere at $37^{\circ} \mathrm{C}$. All cultures were tested mycoplasma-negative by PCR.

\section{Panning of P. falciparum 3D7 parasites on CHO cells}

Selection of IRBC for stationary adhesion to each of the different $\mathrm{CHO}$ cells was carried out basically as previously described [6]. Briefly, trophozoite-stage (26-28 hpi) infected erythrocytes were enriched by Plasmagel ${ }^{\circledR}$ flotation and resuspended in RPMI 1640 pH 6.8 containing $10 \%$ pooled heat-inactivated human plasma. 107-108 IRBC were then incubated with confluent $\mathrm{CHO}$ cell monolayers grown in $25 \mathrm{~cm}^{2}$ culture flasks for $1 \mathrm{~h}$ with gentle agitation every $15 \mathrm{~min}$. Non-adherent infected erythrocytes were washed away three times in RPMI 1640, pH 6.8 by direct aspiration. Bound infected erythrocytes were detached from cells by washing with RPMI 1640, pH 7,4 containing $10 \%$ plasma and returned to culture, adjusting the hematocrit to $5 \%$. Cultures were grown to $2-6 \%$ parasitaemia before repeating this process. Pannings were 
continued until no more increase in adherence was observed (at least 5 times), and the phenotype was maintained by panning every 2-3 weeks. For the quantification of cytoadherence, $5^{*} 10^{6}$ infected red blood cells were panned as above over $90 \%$ confluent CHO-cells (two days after trypsinization) cultivated in $3 \mathrm{~cm}$ diameter culture plates.

\section{RNA isolation, CDNA production and real-time PCR}

Total RNA was isolated from parasites at most two reinvasion cycles after the last panning procedure and the Trizol LS Reagent (Invitrogen) was used as previously described [39]. RNA was then treated with Deoxyribonuclease I (Fermentas) to degrade contaminating genomic DNA. cDNA synthesis was performed with Mu-MLV Reverse Transcriptase (Fermentas) as described by the manufacturer using random hexamer primers (Bioneer). For each cDNA synthesis reaction, a control reaction without reverse transcriptase was done with identical amounts of template.

Real-time qPCRs were carried out using the Realplex 2/2 thermocycler (Eppendorf, Hamburg, Germany). Reactions were performed in $15 \mu \mathrm{l}$ volumes using Biotools QuantiMix EASY SYG KIT (Biotools, B\&M Labs, S.A.) and $0,3 \mathrm{mM}$ of each primer. In order to measure transcription from all var loci present in the 3D7 genome, we employed the previously described primer set [21]. The qPCR conditions were $95^{\circ} \mathrm{C}$ for $2 \mathrm{~min}$ followed by 40 cycles of $95^{\circ} \mathrm{C}$ for $30 \mathrm{~s}, 54^{\circ} \mathrm{C}$ for $40 \mathrm{~s}$, and $68^{\circ} \mathrm{C}$ for $50 \mathrm{~s}$. Specificity of amplification was ascertained by melting-curve analysis of each PCR product. All runs were done in triplicate and yielded virtually identical Ct (cycle threshold) values. The $\Delta \mathrm{Ct}$ for each individual primer pair was determined by subtracting the measured $\mathrm{Ct}$ value from the $\mathrm{Ct}$ value of the control seryl-tRNA synthetase (PF07_0073)[40]. Relative copy numbers (RCN) were then obtained with the formula: $\mathrm{RCN}=2^{-\Delta \mathrm{Ct}}$. Two independent RNAs were tested for each receptor-ligand phenotype. The $\mathrm{Ct}$ values of the internal control were always below 30 cycles.

\section{Cloning and sequencing of $D B L I \alpha$ region}

cDNAs were amplified with the universal DBL1 $\alpha$ primer pair [41], purified from agarose gels and cloned using the InsTA-vector cloning system (Fermentas). For the cDNA from 3D7-Selectin and 3D7-ICAM-1 selected parasites, 32 inserts were sequenced and identified by alignment with fragments of 3D7 from the PlasmoDB website.

\section{Results \\ Panning of 3D7 parasites creates highly adhesive parasites which cross-adhere to $\mathrm{CHO}-745$ cells}

After five rounds of panning on each of the $\mathrm{CHO}$-cell lines the adhesive phenotype remained stable and no further increase in the ratio adhered parasites per $\mathrm{CHO}$-cell was observed. Upon saturating conditions (excess of IRBC over $\mathrm{CHO}$ cells) the adhesive IRBC phenotypes were highly similar for each cell line and the cytoadherence expressed as IRBC/ 100 cells was 300-800 and did not differ consistently between phenotypes. Interestingly, when each CHO-receptor-panned parasite line was analyzed for cytoadherence in CHO-745 cells, all different phenotypes also adhered to these cells, although to a lower amount (100-300 IRBC/100 cells). Upon quantification using fewer parasites than in the cytoadherence selection process, differences in the quantity of adhered parasites were observed (Table 1). 3D7-745, 3D7-ICAM and the 3D7VCAM parasites showed the highest adherence values.

\section{Transcription analysis of selected IRBC indicates a var gene associated with cytoadherence to the unknown receptor on CHO-745 cells}

In the following experiment, parasites selected as above were harvested in young trophozoite stage and their var transcripts analyzed by RT-qPCR (Figure 1). The unselected parasites transcribed mainly the var gene PFL0030c (var2csa), however, only weak adherence of these parasites to CHO-K1 cells was observed ( $<10$ IRBC/100 cells), indicating that cytoadherence to CSA is weak or absent in the 3D7 parasite line. Repeated selection on the CSAknockout CHO-745 cells resulted in increased transcrip-

Table I: Cytoadherence of differently selected 3D7 parasites selected for adhesion on the indicated CHO-cell lines

\begin{tabular}{|c|c|c|c|c|c|c|}
\hline & $\mathrm{CHO}-745$ & $\mathrm{CHO}-\mathrm{KI}$ & $\mathrm{CHO}-\mathrm{CD} 36$ & CHO-ICAM & $\mathrm{CHO}-\mathrm{Sel}$ & CHO-VCAM \\
\hline 3D7 & $7 \pm 2$ & 0 & $12 \pm 4$ & $7 \pm 3$ & $5 \pm 1$ & $4 \pm 2$ \\
\hline $3 \mathrm{D} 7-745$ & $142 \pm 13$ & $120 \pm 23$ & $15 \pm 3$ & $253 \pm 22$ & $28 \pm 5$ & $270 \pm 26$ \\
\hline 3D7-KI & $25 \pm 3$ & $29 \pm 5$ & $32 \pm 8$ & $45 \pm 8$ & $45 \pm 3$ & $34 \pm 4$ \\
\hline 3D7-CD36* & $16 \pm 3$ & $3 \pm 1$ & $62 \pm 7$ & $33 \pm 5$ & $25 \pm 5$ & $23 \pm 6$ \\
\hline 3D7-ICAM* & $40 \pm 9$ & $40 \pm 7$ & $152 \pm 12$ & $235 \pm 18$ & $14 \mid \pm 13$ & $151 \pm 17$ \\
\hline 3D7-Selectin & $13 \pm 2$ & $16 \pm 3$ & $21 \pm 5$ & $50 \pm 8$ & $34 \pm 3$ & $15 \pm 5$ \\
\hline 3D7-VCAM & $51 \pm 11$ & $51 \pm 8$ & $92 \pm 12$ & $226 \pm 21$ & $151 \pm 14$ & $51 \pm 5$ \\
\hline
\end{tabular}

A stock of freshly panned parasites was thawed, put into culture and after 4-6 reinvasions, 5*106 IRBC (at trophozoite stage) were incubated on the indicated $\mathrm{CHO}$-cell lines, washed and counted. For each cell line, 1000 cells and the adhering parasites were counted and cytoadherence was expressed as IRBC per 100 cells. Phenotypes which significantly (Chi-square method, $p<0,05$ ) adhered more to the $\mathrm{CHO}$ cell line for which they were selected than to any other cell line are marked with an asterisk. 


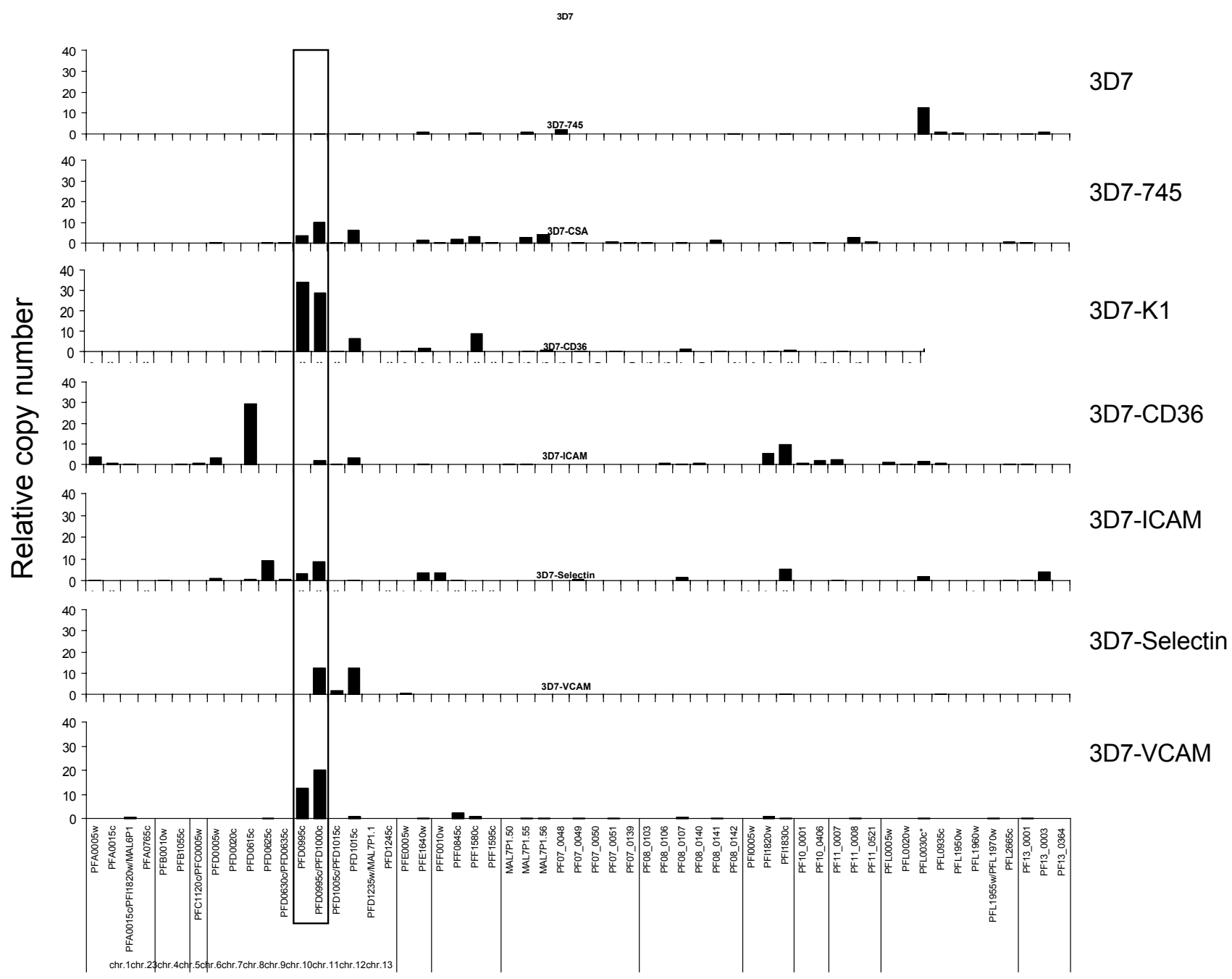

Figure I

var transcription in different adhesive 3D7 phenotypes. Transcription levels were measured by real-time PCR using primers specific for each of the 57 different var genes identified in the $P$. falciparum 3D7 genome. All values are presented as relative copy numbers, calibrated to the housekeeping gene seryl-tRNA synthetase (PF07_0073). Top panel: Transcription pattern of 3D7 wildtype parasites demonstrated low var gene expression in general. Second panel: 3D7 parasites selected on CHO-475 cells demonstrated expression of var genes located on chromosome 4 - PFD0995c/PFDI000c, similar to 3D7 parasites selected on CHO-KI cells (CHO-CSA, Third panel). Fourth panel: 3D7-CD36 demonstrated expression of the PFD06I5c var gene located on chromosome 4, but not the CHO-745 related var genes PFD0995c/PFDI000c. Fifth panel: 3D7-ICAMI cells transcribed PFD0625c but also PFD0995c/PFDI000c. Sixth panel: 3D7 parasites selected on CHO-Selectin cells showed expression of PFDI000c and PFDI0I5c on chromosome 4. Seventh panel: 3D7-VCAM parasites transcribed PFD0995c/ PFDI000c and did not show any other upregulated var gene.

tion of PFD995c/PFD1000c var genes, which share similar promoters and approximately $2831 \mathrm{nt}$ in the 5 'portion of each gene $[42,43]$. Other var genes from chromosomes 6 , 7 and 11 were also found in higher quantities. Notably, upon selection on CHO-K1 (unmodified, CSA expressing cell line), the same dominant transcript PFD0995c was obtained and transcripts from var locus PFF1580c on chromosome 6 were also detected.

When parasites were selected on CHO-CD36, no significant amounts of the PFD0995/1000c transcripts were observed, instead, transcription from the PFD0615c locus 
was activated. Also, minor quantities of var transcripts from chromosome 9 were observed. Interestingly, this parasite line also bound well to untransfected CHO-745 cells (Table 1 ).

The selection of 3D7 on CHO-ICAM-1 demonstrated the transcription of principally PFD995c/1000c and PFD0625c. A number of other var loci were also found active, principally on chromosomes 5, 6, 9 and 13 .

The selection of cytoadherent parasites on CHO-Selectin cells yielded a parasite line expressing two main var transcripts PFD1000c and PFD1015c while all other var loci seemed silenced. In the last experiment, the transcripts of CHO-VCAM selected 3D7 parasites were monitored. As shown in Figure 1, var transcription occurred almost exclusively from the var locus PFD995c/1000c. Since the primer pair for PFD0995c/PFD1000c co-amplifies PFD0995C and PFD1000c, and the PFD0995c transcript alone was found in higher quantities, most transcripts seem to originate from the PFD0995c locus, similar to 3D7-K1 but in contrast to 3D7-745 parasites, which show more transcripts from the PFD1000 locus.

The herein used stationary assay of cytoadherence is believed to select for the strongest binding parasite phenotype. In order to elucidate from which promoter type the most abundant transcripts were generated, the relative var transcript copy numbers of each transcript were grouped corresponding to their promoter type upsA, B, C, $\mathrm{D}$ and E. As shown in Figure 2, most of the transcribed var genes were from ups $\mathrm{C}$ promoters, even when omitting the signal from the PFD0995/PFD1000c locus.
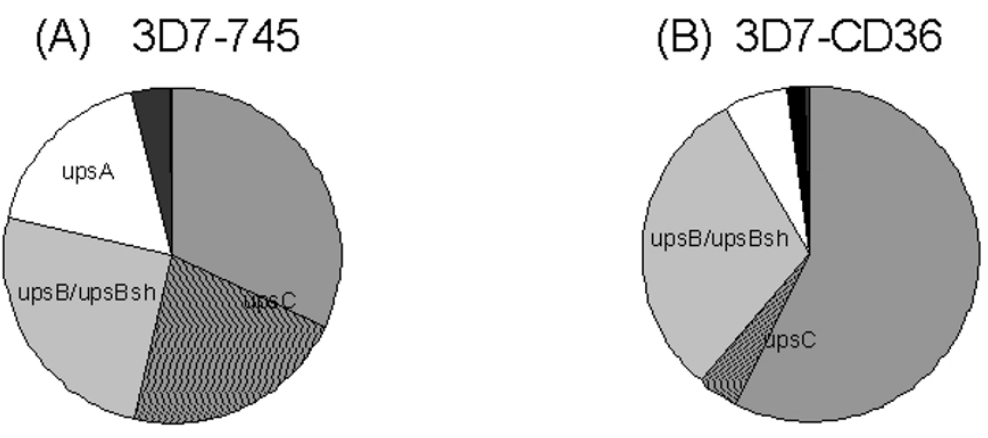

(C) 3D7-ICAM
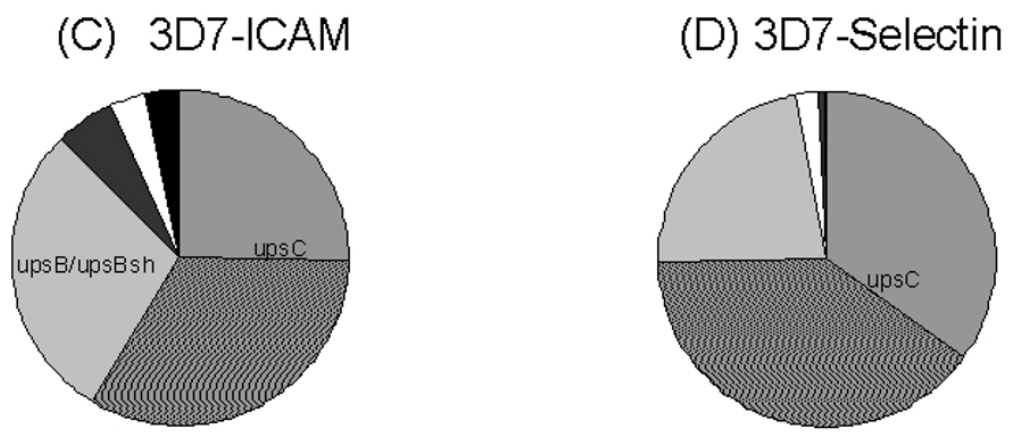

\section{upsA $\square$ upsB/upsBsh $\square$ upsC UpsC and PFD0995 and PFD1000c}

\section{$\square$ upsD $\square$ upsE}

\section{Figure 2}

var promoter profile of different adhesive parasites phenotypes. The pie charts present relative levels of transcription of each var promoter type from parasites selected on - ups A, upsB/upsBsh, upsC, upsD and upsE. In hatched dark grey, the fraction of transcripts from upsC var genes PFD0995/PFDI000c are highlighted. 


\section{Significant differences of detected var transcripts by $R T$ - PCRcsc versus $R T$-qPCR analysis}

Var gene transcription in field isolates was frequently analyzed by RT-PCR analysis followed by cloning and semiquantitative clone analysis [44-47] and due to the high var gene variability this is the only method to monitor var gene transcription in field isolates. In the following, an evaluation was done whether var transcription measured by RT-PCRcsc matched the results obtained by RT-qPCR. Two adhesive phenotypes were selected for this analysis: The CHO-Selectin phenotype which shows the transcription of the var genes PFD1000 and PFD1015c and the CHO-ICAM-1 phenotype which shows the CHO-745 associated PFD995/1000c transcript plus the possibly ICAM-1-binding related PFD0625c transcript.

After RT-PCR and cloning of fragments generated on RNAs also used in the RT-qPCR experiment, the dominant transcripts were compared, deduced from the number of sequence reads, with the GPCR results. Surprisingly, the dominant transcript in CHO-Selectin selected parasites was exclusively PFD0995c/PFD1000c and not a single clone carrying the PFD1015c transcript was observed by this method (Figure 3). When RNA from the CHO-ICAM1 selected parasites was analysed, the mainly observed transcript was PFD0995c/PFD1000c and the second abundant transcript was PFF0845c. The var1csa transcript (PFE1640w, truncated in 3D7 parasites), was also detected. However, the transcript PFD0625c was not observed (Figure 3 ). Taken together, these data indicate that in the conditions applied herein, RT-PCR followed by fragment cloning and sequence read analysis leads to results different from those obtained by RT-qPCR.

\section{Discussion}

In the present study, a practical and simple system for the analysis and selection of $P$. falciparum adhesive phenotypes and their var transcripts was evaluated. This system was so far used only for the diagnosis of cytoadherent $P$. falciparum isolates [31,44], but not for the deliberate selection and enrichment of adhesive phenotypes for posterior ligand-receptor interaction or other analyses. Most of the herein used receptors are also commercially available as purified molecules, however, either these molecules are so expensive that they turn the use in quantitative selection experiments unviable or they are not displayed properly for recognition upon coating of supports such as Petri dishes or culture flasks. Also, in the case of ICAM-1 and CD36, free ICAM-1 or CD36 molecules do not detach IRBC interacting with these molecules on the cell surface, although interaction may be abrogated by specific antibodies against ICAM-1 or CD36 [48]. Therefore, the selection of parasites by specific detachment of adhered parasites, as it is feasible for the interaction of IRBC with
CSA expressed on Saimiri brain endothelial cells [49], proved impossible.

A major handicap of the herein used system is the yet unknown receptor present on CHO-745 cells which is readily recognized by $3 \mathrm{D} 7$ parasites as previously described [32]. These authors demonstrated a phenotype which could be inhibited by anti-CD36 monoclonal antibody, indicating that CHO-745 may carry a CD36-like receptor on its surface. They also showed that protein $\mathrm{A}$ pretreated parasites were significantly cytoadherenceinhibited (although adhesion was not totally abrogated) indicating also an interference with opsonizing IgM antibodies. Since the binding ligand of 3D7 IRBC selected on CHO-745 was trypsin sensitive, the hypothesis was that the interaction IRBC to CHO-745 may at least partly be caused by PfEMP1 and anticipated the detection of specific var transcripts, which encode the PfEMP1 responsible for this unknown receptor. Considering the existence of this unknown receptor and supposedly uniform transgene-receptor expression on CHO-CD36, CHO-VCAM, CHO-ICAM-1, CHO-Selectin and CHO-K1 (not specifically tested for herein), the model will only be able to select for strong binding ligands, since IRBC will otherwise be selected for the unknown receptor. Its appearance in all but one selected 3D7 parasite line suggests the possibility that the unknown receptor is recognized by PfEMP1 encoded by PFD0995c/PFD1000c.

Upon analysis of the transcription profile of 3D7 selected on CSA-expressing CHO-K1 cells, no specific increased transcript abundance of var2csa was observed. In contrast to the FCR3 strain, the 3D7 parasite line was only poorly selectable on purified fixed CSA (data not shown and [21]). In a panning experiment using purified CSA, the 3D7 strain also showed decreased affinity for this receptor in comparison to other strains [50]. This possibly explains why no var2csa upregulation was observed, and the var transcription profile was somehow similar to the CHO745-panned parasites. Other authors obtained the var2csa transcribing phenotype by the selection of NF54 which is isogenic with 3D7 [21,51]. A similar effect was observed for the CHO-VCAM phenotype, although it is unknown if 3D7 encodes a competent ligand for this molecule. To date, no var gene in any strain was associated to VCAMadhesion, although this receptor seems recognizable by PfEMP1 [52]. Strong ligands with high binding affinities are expected to override adhesion to the unknown receptor. In the case of 3D7, CD36 seems to be readily recognized and the CHO-CD36 adherent parasites contained very low levels of the PFD0995c/PFD1000c transcript. On the other hand, 3D7-CD36 parasites also adhered to CHO-745 cells, as seen already by other groups [32], without transcribing PFD0995c/PFD1000c. The most abundant var transcript in this parasite line was PFD0615c. 

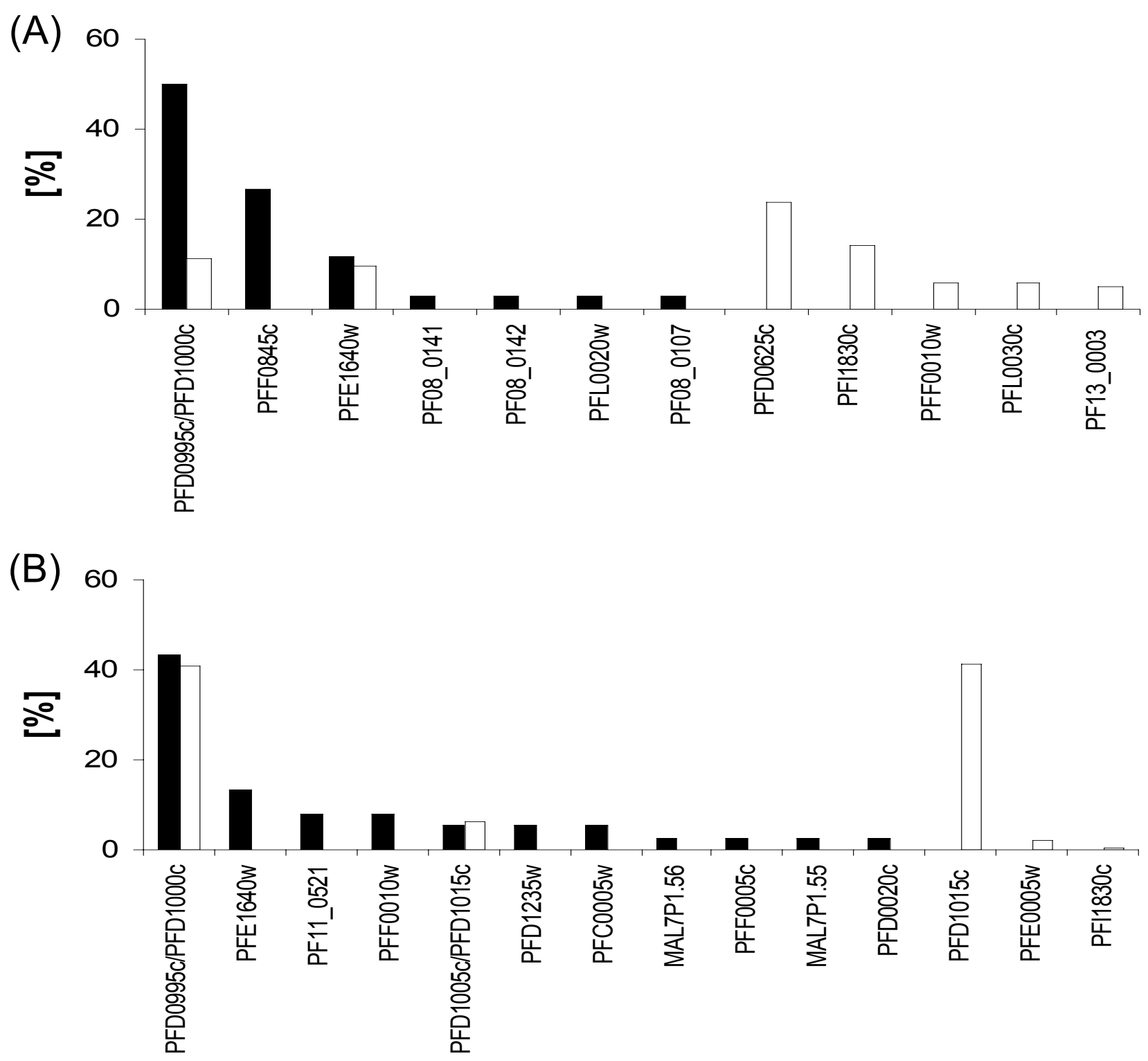

Figure 3

A comparison of RT-PCRcsc and RT-qPCR methods. 32 clones of each RT-PCRcsc experiment were sequenced and the sequence reads plotted against the sequence ID of each tag (black bars). In white bars the results for RT-qPCR are shown. (A) 3D7-ICAM-I (B) 3D7-Selectin.

Although never functionally examined, this gene contains a CIDR domain which is grouping with other CIDR domains that are in fact CD36 binder [43]. This indicates that PFD0615c encodes a stronger binding CIDR domain than PFD0995c/PFD1000c, considered as a moderate CIDR-binder [43]. The cytoadherence of 3D7-CD36 to each other cell line including $\mathrm{CHO}-745$ may be explained by the assumption that the recognized although unknown receptor on CHO-745 is CD36-like as proposed by Andrews and colleagues [32].

E-Selectin was detected as a receptor for cytoadherence [52], yet, no isolate or strain was specifically selected for this specific phenotype. Also, cytoadherence to this receptor seems to be a rare event [53] and was never clearly identified as the cause of severe malaria, although E-Selec- 
tin in its soluble form is increased in acute phase malaria [54]. It is also unknown which PfEMP1-domain mediates cytoadherence to E-Selectin. In our studies, the var transcript PFD1015 was clearly associated to CHO-E-Selectin adherence. In addition the var gene PFD1000c representing the supposed ligand for the unknown receptor of CHO-745 cells was also present, explaining the crossadherence to CHO-745 and other CHO cells. The cytoadherence to CHO-ICAM-1 showed that transcript PFD0625c was found in elevated levels. Since ICAM-1, as well as CD36, is a relative abundant receptor in man, a number of competent PfEMP1 molecules are expected to be present in the 3D7 parasite line. Indeed, a couple o var genes were found transcribed together with the CHO-745 specific transcripts PFD0995C/PFD1000c. The var gene PFD0625c, however, contains no DBL $\beta / C 2$ domain important for ICAM-1-binding [55,56], indicating that this var gene may not encode the ICAM-1-recognizing PfEMP1. Interestingly, other authors found a comparable result when analysing var transcripts by microarray analysis. Upon multiple pannings on purified ICAM-1 the most transcribed $v$ ar gene detected did not contain a DBL- $\beta / C 2$ domain [50]. In another study, still another var gene than PFD0625c was found in 3D7 parasites selected for ICAM1 adhesion [57]. This indicates that it is not clear whether the CHO-ICAM-1 adhesive phenotype really binds to human ICAM-1.

The relative transcript quantities against their corresponding upstream regions were then clustered [58]. Most of the transcripts in selected parasites were from upsC and upsB promoters and only in minor quantities transcripts from subtelomeric locations were observed, even when discarding the dominantly found PFD0995c/1000c transcript. It is possible that strong binding PfEMP1-coding var genes are found in centromeric localizations, while weaker binding PfEMP1 molecules are encoded by subtelomeric var genes, prone to ectopic recombination and rearrangements [59]. Clearly, the unambiguous identification of ligands and receptors is necessary and may confirm or refute this hypothesis.

The analysis of transcripts by the to-date unique applicable system of transcript analysis in field isolates showed a significant discordance to the results obtained in RTqPCR. Of the two main transcripts that were highly represented in the CHO-Selectin binding parasites, only the PFD1000c transcript was detected by clone analysis. A similar result was shown before using even another primer pair binding upstream of the universal var oligonucleotides [47]. In a similarly designed study, Gatton and coworkers also postulated that the PFD1015c DBL $\alpha$ fragment may not be amplified by the universal var oligos [60]. It is puzzling why the PFD1015 DBL1 $\alpha$ tag was not even cloned once, since it has perfect target site for the universal oligonucleotide pair used herein. In more than 500 sequence reads from diverse 3D7 cDNAs, the PFD1015 var DBL1 $\alpha$ tag was encountered only once. Notably, in other studies amplifying either genomic or transcribed targets $[41,57,61]$ the PFD $1015 \mathrm{c}$ tag was also never observed. The discrepancy of the two approaches was also observed in other adhesive phenotypes, however, the CDNAs used in these experiments were not from the same lot as the ones tested herein by qRT-PCR (Table 2). Assuming that RT-qPCR using the described primer set is the most reliable experimental procedure to study var gene transcription in 3D7, the RT-PCR/cloning approach is highly misleading and not reflecting true transcript quantities, at least in the conditions used herein. This implies that data from field samples analysed by this

Table 2: Sequence read distribution in cDNA produced from 3D7 parasites panned on CHO-745, CHO-KI, CHO-CD36 and CHOVCAM.

\begin{tabular}{|c|c|c|c|c|}
\hline $\begin{array}{l}\text { var transcript from } \\
\text { locus }\end{array}$ & 3D7_745 & 3D7_CSA & 3D7_CD36 & 3D7_VCAM \\
\hline PF07_005I & & & $1 / 29$ & $1 / 17$ \\
\hline PF08_0107 & $3 / 30$ & & & \\
\hline PFIO_00I & & & $1 / 29$ & \\
\hline PFD0615c & $16 / 30$ & $7 / 16$ & $25 / 29$ & $1 / 17$ \\
\hline PFD0635c & $1 / 30$ & & & \\
\hline PFD0995c & & & & $3 / 17$ \\
\hline PFDI000c & $3 / 30$ & $1 / 16$ & $1 / 29$ & \\
\hline PFDI0I5c & & $1 / 16$ & & \\
\hline PFF0845C & $6 / 30$ & $7 / 16$ & & $1 / 17$ \\
\hline PFFI580c & & & $1 / 29$ & \\
\hline PFL0020w & $1 / 30$ & & & $1 / 17$ \\
\hline PFLI970w & & & & $10 / 17$ \\
\hline
\end{tabular}

A varying number of clones stemming from the ligation of a RT-PCR fragment of the indicated parasite lines was analysed as described. The resulting sequences are indicated on the left. 
method may also not display the true transcript levels in the corresponding parasites. There is no simple explanation for these differences between the two methods. Either, certain quantities of 3'-truncated transcripts are present, which can be reverse transcribed and amplified by DBL1 $\alpha$ specific primers. However, two groups recently demonstrated that there is no "relaxed" transcription in ring stage parasites $[5,62]$ and thus no significant accumulation of 3'-truncated transcripts. On the other hand, it may be speculated that an existing primer bias is exacerbated upon amplification of cDNA due to secondary structures interfering with the processivity of the Taq polymerase. Taken together, our data suggest caution when trying to correlate var transcripts detected by RTPCRcsc from field isolates to clinical outcomes. The selection of parasites on transfected CHO-cells revealed reproducibly different patterns of var transcription in dependence on which $\mathrm{CHO}$ cell line was used which may be used in further analyses of receptor-ligand studies or, for example, for the elucidation of transcriptional activation or silencing of var loci without the need for transfection of artificial var promoters.

\section{Conclusion}

Cytoadherence selection of $P$. falciparum parasites using $\mathrm{CHO}$ cells is significantly hindered by the existence of a competent receptor on the $\mathrm{CHO}$ cell lineage. This suggests that the interaction of $P$. falciparum 3D7 IRBC to this perhaps CD36-like receptor is mediated by the PfD0995c/ 1000c encoded PfEMP1. Comparative analysis of RTPCRcsc and RT-qPCR revealed that RT-PCRcsc is misleading when interpreting var transcription.

\section{Authors' contributions}

UG and LA carried out the panning of parasites, the RTqPCR and transcription analysis. UG, LA and GW conceived the design of the study, wrote and approved the final manuscript.

\section{Acknowledgements}

This work was supported by grants from the Fundação de Amparo à Pesquisa do Estado de São Paulo (FAPESP grant 06/5 I873-0). UG and LA were supported by a PhD fellowship from FAPESP. GW is a CNPq fellow.

\section{References}

I. Snow RW, Guerra CA, Noor AM, Myint HY, Hay SI: The global distribution of clinical episodes of Plasmodium falciparum malaria. Nature 2005, 434(7030):2 I4-2I7.

2. Leech JH, Barnwell JW, Miller LH, Howard RJ: Identification of a strain-specific malarial antigen exposed on the surface of Plasmodium falciparum-infected erythrocytes. I Exp Med 1984, I59(6): I567-I575.

3. Sherman IW, Eda S, Winograd E: Cytoadherence and sequestration in Plasmodium falciparum: defining the ties that bind. Microbes Infect 2003, 5( I 0):897-909.

4. Miller LH, Baruch DI, Marsh K, Doumbo OK: The pathogenic basis of malaria. Nature 2002, 4I5(6872):673-679.

5. Kyes S, Christodoulou Z, Pinches R, Kriek N, Horrocks P, Newbold $\mathrm{C}$ : Plasmodium falciparum var gene expression is developmentally controlled at the level of RNA polymerase II-medi- ated transcription initiation. Mol Microbiol 2007, 63(4): 1237-1247.

6. Scherf A, Hernandez-Rivas R, Buffet P, Bottius E, Benatar C, Pouvelle $B$, Gysin J, Lanzer M: Antigenic variation in malaria: in situ switching, relaxed and mutually exclusive transcription of var genes during intra-erythrocytic development in Plasmodium falciparum. Embo J 1998, I 7( I 8):5418-5426.

7. Chen Q, Fernandez V, Sundstrom A, Schlichtherle M, Datta S, Hagblom $P$, Wahlgren M: Developmental selection of var gene expression in Plasmodium falciparum. Nature 1998, 394(669 ):392-395.

8. Ralph SA, Scheidig-Benatar C, Scherf A: Antigenic variation in Plasmodium falciparum is associated with movement of var loci between subnuclear locations. Proc Natl Acad Sci U S A 2005, I02(15):54|4-54|9.

9. Voss TS, Healer J, Marty AJ, Duffy MF, Thompson JK, Beeson JG, Reeder JC, Crabb BS, Cowman AF: A var gene promoter controls allelic exclusion of virulence genes in Plasmodium falciparum malaria. Nature 2006, 439(7079): 1004-1008.

10. Dzikowski R, Li F, Amulic B, Eisberg A, Frank M, Patel S, Wellems TE, Deitsch KW: Mechanisms underlying mutually exclusive expression of virulence genes by malaria parasites. $E M B O R e p$ 2007.

II. Duraisingh MT, Voss TS, Marty AJ, Duffy MF, Good RT, Thompson JK, Freitas-Junior LH, Scherf A, Crabb BS, Cowman AF: Heterochromatin silencing and locus repositioning linked to regulation of virulence genes in Plasmodium falciparum. Cell 2005, I2I(I): 13-24.

12. Freitas-Junior LH, Hernandez-Rivas R, Ralph SA, Montiel-Condado D, Ruvalcaba-Salazar OK, Rojas-Meza AP, Mancio-Silva L, Leal-Silvestre RJ, Gontijo AM, Shorte S, Scherf A: Telomeric heterochromatin propagation and histone acetylation control mutually exclusive expression of antigenic variation genes in malaria parasites. Cell 2005, I 2 I (I):25-36.

13. Chookajorn T, Dzikowski R, Frank M, Li F, Jiwani AZ, Hartl DL, Deitsch KW: Epigenetic memory at malaria virulence genes. Proc Natl Acad Sci U S A 2007, I 04(3):899-902.

14. Lopez-Rubio JJ, Gontijo AM, Nunes MC, Issar N, Hernandez Rivas R, Scherf A: 5 ' flanking region of var genes nucleate histone modification patterns linked to phenotypic inheritance of virulence traits in malaria parasites. Mol Microbiol 2007, 66(6): 1296-1305.

15. Roberts DJ, Craig AG, Berendt AR, Pinches R, Nash G, Marsh K, Newbold Cl: Rapid switching to multiple antigenic and adhesive phenotypes in malaria. Nature 1992, 357(6380):689-692.

16. Horrocks P, Pinches R, Christodoulou Z, Kyes SA, Newbold Cl: Variable var transition rates underlie antigenic variation in malaria. Proc Natl Acad Sci U S A 2004, I 0 I(30): I I I 29- I I I 34.

17. Choi SW, Keyes MK, Horrocks P: LC/ESI-MS demonstrates the absence of 5-methyl-2'-deoxycytosine in Plasmodium falciparum genomic DNA. Mol Biochem Parasitol 2006, I50(2):350-352.

18. Newbold C, Warn P, Black G, Berendt A, Craig A, Snow B, Msobo M, Peshu N, Marsh K: Receptor-specific adhesion and clinical disease in Plasmodium falciparum. Am J Trop Med Hyg 1997, 57(4):389-398.

19. Rogerson SJ, Tembenu R, Dobano C, Plitt S, Taylor TE, Molyneux ME: Cytoadherence characteristics of Plasmodium falciparuminfected erythrocytes from Malawian children with severe and uncomplicated malaria. Am J Trop Med Hyg 1999, 6I(3):467-472.

20. Fried M, Duffy PE: Adherence of Plasmodium falciparum to chondroitin sulfate $\mathbf{A}$ in the human placenta. Science 1996, 272(5267): 1502-1504.

21. Salanti A, Staalsoe T, Lavstsen T, Jensen AT, Sowa MP, Arnot DE, Hviid L, Theander TG: Selective upregulation of a single distinctly structured var gene in chondroitin sulphate $\mathbf{A}$-adhering Plasmodium falciparum involved in pregnancyassociated malaria. Mol Microbiol 2003, 49(1): 179-191.

22. Gamain B, Smith JD, Avril M, Baruch DI, Scherf A, Gysin J, Miller LH: Identification of a 67-amino-acid region of the Plasmodium falciparum variant surface antigen that binds chondroitin sulphate $A$ and elicits antibodies reactive with the surface of placental isolates. Mol Microbiol 2004, 53(2):445-455.

23. Chattopadhyay R, Taneja T, Chakrabarti K, Pillai CR, Chitnis CE: Molecular analysis of the cytoadherence phenotype of a Plas- 
modium falciparum field isolate that binds intercellular adhesion molecule- I. Mol Biochem Parasitol 2004, I33(2):255-265.

24. Tuikue Ndam NG, Salanti A, Bertin G, Dahlback M, Fievet N, Turner L, Gaye A, Theander T, Deloron P: High level of var2csa transcription by Plasmodium falciparum isolated from the placenta. J Infect Dis 2005, 192(2):331-335.

25. Baruch DI, Gamain B, Barnwell JW, Sullivan JS, Stowers A, Galland GG, Miller LH, Collins WE: Immunization of Aotus monkeys with a functional domain of the Plasmodium falciparum variant antigen induces protection against a lethal parasite line. Proc Natl Acad Sci U S A 2002, 99(6):3860-3865.

26. Chia YS, Badaut C, Tuikue Ndam NG, Khattab A, Igonet S, Fievet N, Bentley GA, Deloron P, Klinkert MQ: Functional and immunological characterization of a duffy binding-like- gamma domain from Plasmodium falciparum erythrocyte membrane protein-I expressed by a placental isolate. J Infect Dis 2005, I 92(7): 1284- 1293.

27. Barnwell JW, Ockenhouse CF, Knowles DM 2nd: Monoclonal antibody OKM5 inhibits the in vitro binding of Plasmodium falciparum-infected erythrocytes to monocytes, endothelial, and C32 melanoma cells. J Immunol 1985, I35(5):3494-3497.

28. Gay F, Robert C, Pouvelle B, Peyrol S, Scherf A, Gysin J: Isolation and characterization of brain microvascular endothelial cells from Saimiri monkeys. An in vitro model for sequestration of Plasmodium falciparum-infected erythrocytes. J Immunol Methods 1995, 184(I): 15-28.

29. Muanza K, Gay F, Behr C, Scherf A: Primary culture of human lung microvessel endothelial cells: a useful in vitro model for studying Plasmodium falciparum-infected erythrocyte cytoadherence. Res Immunol 1996, I47(3): I49-163.

30. Viebig NK, Nunes MC, Scherf A, Gamain B: The human placental derived BeWo cell line: a useful model for selecting Plasmodium falciparum CSA-binding parasites. Exp Parasitol 2006, I I 2(2): | $2 \mid-125$

31. Hasler T, Albrecht GR, Van Schravendijk MR, Aguiar JC, Morehead KE, Pasloske BL, Ma C, Barnwell JW, Greenwood B, Howard RJ: An improved microassay for Plasmodium falciparum cytoadherence using stable transformants of Chinese hamster ovary cells expressing CD36 or intercellular adhesion molecule-I. Am J Trop Med Hyg 1993, 48(3):332-347.

32. Andrews KT, Adams Y, Viebig NK, Lanzer M, Schwartz-Albiez R: Adherence of Plasmodium falciparum infected erythrocytes to $\mathrm{CHO-745}$ cells and inhibition of binding by protein $A$ in the presence of human serum. Int J Parasitol 2005, 35(I0): I | 27-I I34.

33. Buffet PA, Gamain B, Scheidig C, Baruch D, Smith JD, HernandezRivas R, Pouvelle B, Oishi S, Fujii N, Fusai T, Parzy D, Miller LH, Gysin J, Scherf A: Plasmodium falciparum domain mediating adhesion to chondroitin sulfate $A$ : a receptor for human placental infection. Proc Natl Acad Sci U S A 1 999, 96(22): I 2743-I 2748.

34. Walliker D, Quakyi IA, Wellems TE, McCutchan TF, Szarfman A, London WT, Corcoran LM, Burkot TR, Carter R: Genetic analysis of the human malaria parasite Plasmodium falciparum. Science 1987, 236(4809): 166 I-1666.

35. Lambros C, Vanderberg JP: Synchronization of Plasmodium falciparum erythrocytic stages in culture. J Parasitol 1979, 65(3):418-420.

36. Trager $\mathrm{W}$, Jensen JB: Human malaria parasites in continuous culture. Science 1976, 193(4254):673-675.

37. Esko JD, Stewart TE, Taylor WH: Animal cell mutants defective in glycosaminoglycan biosynthesis. Proc Natl Acad Sci U S A 1985, 82(10):3197-320|.

38. Esko JD, Weinke JL, Taylor WH, Ekborg G, Roden L, Anantharamaiah G, Gawish A: Inhibition of chondroitin and heparan sulfate biosynthesis in Chinese hamster ovary cell mutants defective in galactosyltransferase I. J Biol Chem 1987, 262(25): I2I89-12195.

39. Kyes SA, Pinches R, Newbold C: A simple RNA analysis method shows var and rif multigene family expression patterns in Plasmodium falciparum. Mol Biochem Parasitol 2000, 105(2):3||-3|5.

40. Applied Biosystems User Bulletin 2 [http://www3.appliedbio systems.com/cms/groups/mcb support/documents/generaldocu ments/cms 040980.pdf]

41. Taylor HM, Kyes SA, Harris D, Kriek N, Newbold Cl: A study of var gene transcription in vitro using universal var gene primers. Mol Biochem Parasitol 2000, 105(I): 13-23.
42. Kraemer SM, Kyes SA, Aggarwal G, Springer AL, Nelson SO, Christodoulou Z, Smith LM, Wang W, Levin E, Newbold Cl, Myler PJ, Smith JD: Patterns of gene recombination shape var gene repertoires in Plasmodium falciparum: comparisons of geographically diverse isolates. BMC Genomics 2007, 8:45.

43. Robinson BA, Welch TL, Smith JD: Widespread functional specialization of Plasmodium falciparum erythrocyte membrane protein I family members to bind CD36 analysed across a parasite genome. Mol Microbiol 2003, 47(5): I265- I 278.

44. Afonso Nogueira P, Wunderlich G, Shugiro Tada M, d'Arc Neves Costa J, Jose Menezes M, Scherf A, Pereira-da-Silva LH: Plasmodium falciparum: analysis of transcribed var gene sequences in natural isolates from the Brazilian Amazon region. Exp Parasitol 2002, I0I(2-3): III-120.

45. Kaestli M, Cortes A, Lagog M, Ott M, Beck HP: Longitudinal assessment of Plasmodium falciparum var gene transcription in naturally infected asymptomatic children in Papua New Guinea. J Infect Dis 2004, I 89( I 0): I942-195I.

46. Bull PC, Berriman M, Kyes S, Quail MA, Hall N, Kortok MM, Marsh $\mathrm{K}$, Newbold $\mathrm{Cl}$ : Plasmodium falciparum variant surface antigen expression patterns during malaria. PLoS Pathog 2005, I(3):e26.

47. Wunderlich G, Alves FP, Golnitz U, Tada MS, Camargo EF, Pereirada-Silva LH: Rapid turnover of Plasmodium falciparum var gene transcripts and genotypes during natural non-symptomatic infections. Rev Inst Med Trop Sao Paulo 2005, 47(4): 195-20I.

48. Baratin M, Roetynck S, Pouvelle B, Lemmers C, Viebig NK, Johansson $S$, Bierling P, Scherf A, Gysin J, Vivier E, Ugolini S: Dissection of the role of PfEMPI and ICAM-I in the sensing of plasmodium falciparum-infected erythrocytes by natural killer cells. PLOS ONE 2007, 2(2):e228.

49. Lekana Douki JB, Traore B, Costa FT, Fusai T, Pouvelle B, Sterkers Y, Scherf A, Gysin J: Sequestration of Plasmodium falciparuminfected erythrocytes to chondroitin sulfate $A$, a receptor for maternal malaria: monoclonal antibodies against the native parasite ligand reveal pan-reactive epitopes in placental isolates. Blood 2002, 100(4): |478-| 483.

50. Duffy MF, Byrne TJ, Elliott SR, Wilson DW, Rogerson SJ, Beeson JG, Noviyanti $R$, Brown GV: Broad analysis reveals a consistent pattern of var gene transcription in Plasmodium falciparum repeatedly selected for a defined adhesion phenotype. Mol Microbiol 2005, 56(3):774-788.

5I. Dzikowski R, Frank M, Deitsch K: Mutually exclusive expression of virulence genes by malaria parasites is regulated independently of antigen production. PLoS Pathog 2006, 2(3):e22.

52. Ockenhouse CF, Tegoshi T, Maeno Y, Benjamin C, Ho M, Kan KE, Thway Y, Win K, Aikawa M, Lobb RR: Human vascular endothelial cell adhesion receptors for Plasmodium falciparuminfected erythrocytes: roles for endothelial leukocyte adhesion molecule I and vascular cell adhesion molecule I. J Exp Med 1992, I 76(4): I I83-II89.

53. Udomsangpetch R, Taylor BJ, Looareesuwan S, White NJ, Elliott JF, Ho M: Receptor specificity of clinical Plasmodium falciparum isolates: nonadherence to cell-bound E-selectin and vascular cell adhesion molecule-I. Blood 1996, 88(7):2754-2760.

54. Hviid L, Theander TG, Elhassan IM, Jensen JB: Increased plasma levels of soluble ICAM-I and ELAM-I (E-selectin) during acute Plasmodium falciparum malaria. Immunol Lett 1993, 36(I):5I-58.

55. Smith JD, Craig AG, Kriek N, Hudson-Taylor D, Kyes S, Fagan T, Pinches R, Baruch DI, Newbold Cl, Miller LH: Identification of a Plasmodium falciparum intercellular adhesion molecule-I binding domain: a parasite adhesion trait implicated in cerebral malaria. Proc Natl Acad Sci U S A 2000, 97(4): I766- I77|

56. Springer AL, Smith LM, Mackay DQ, Nelson SO, Smith JD: Functional interdependence of the DBLbeta domain and c2 region for binding of the Plasmodium falciparum variant antigen to ICAM-I. Mol Biochem Parasitol 2004, I 37(I):55-64.

57. Noviyanti R, Brown GV, Wickham ME, Duffy MF, Cowman AF, Reeder JC: Multiple var gene transcripts are expressed in Plasmodium falciparum infected erythrocytes selected for adhesion. Mol Biochem Parasitol 200 I, I I 4(2):227-237.

58. Lavstsen T, Salanti A, Jensen AT, Arnot DE, Theander TG: Subgrouping of Plasmodium falciparum 3D7 var genes based on sequence analysis of coding and non-coding regions. Malar J 2003, 2:27. 
59. Freitas-Junior LH, Bottius E, Pirrit LA, Deitsch KW, Scheidig C, Guinet $F$, Nehrbass $U$, Wellems TE, Scherf A: Frequent ectopic recombination of virulence factor genes in telomeric chromosome clusters of P. falciparum. Nature 2000, 407(6807): $1018-1022$.

60. Gatton ML, Peters JM, Gresty K, Fowler EV, Chen N, Cheng Q: Detection sensitivity and quantitation of Plasmodium falciparum var gene transcripts by real-time RT-PCR in comparison with conventional RT-PCR. Am J Trop Med Hyg 2006, 75(2):2। 2-2।8.

61. Peters J, Fowler E, Gatton M, Chen N, Saul A, Cheng Q: High diversity and rapid changeover of expressed var genes during the acute phase of Plasmodium falciparum infections in human volunteers. Proc Natl Acad Sci U S A 2002, 99( I6): I0689-10694.

62. Schieck E, Pfahler JM, Sanchez CP, Lanzer M: Nuclear run-on analysis of var gene expression in Plasmodium falciparum. Mol Biochem Parasitol 2007, I53(2):207-2I 2.

Publish with Bio Med Central and every scientist can read your work free of charge

"BioMed Central will be the most significant development for disseminating the results of biomedical research in our lifetime. "

Sir Paul Nurse, Cancer Research UK

Your research papers will be:

- available free of charge to the entire biomedical community

- peer reviewed and published immediately upon acceptance

- cited in PubMed and archived on PubMed Central

- yours - you keep the copyright 